\title{
Biosorption Potential of the Aspergillus sp. and Insights into Secondary Metabolism in the Presence of Copper and Lead
}

\author{
Maurício Augusto P. M. S. Alves, ${ }^{a}$ Sebastião C. Silva, ${ }^{a}$ Simone Y. S. Silva, ${ }^{a}$ \\ João B. Pereira Junior, ${ }^{\circledR a}$ Patrícia S. B. Marinho, ${ }^{b}$ Kelly das Graças F. Dantas, ${ }^{b}$ \\ Silvio Alex P. da Mota, ${ }^{a}$ Jessica Cristina Amaral, ${ }^{c}$ Maria Fátima G. F. da Silva ${ }^{\circledR c}$ \\ and Marilene N. Oliveira ${ }^{\circledR *} *$ \\ anstituto de Ciências Exatas, Universidade Federal do Sul e Sudeste do Pará, \\ 68505-080 Marabá-PA, Brazil \\ ${ }^{b}$ Instituto de Ciências Exatas e Naturais, Universidade Federal do Pará, \\ 66075-110 Belém-PA, Brazil \\ 'Departamento de Química, Centro de Ciências Exatas e de Tecnologia, \\ Universidade Federal de São Carlos, 13565-905 São Carlos-SP, Brazil
}

\begin{abstract}
The fungus Aspergillus sp. was isolated from copper mining rejects and cultured in a liquid culture medium (potato dextrose, $\mathrm{PD}$ ) enriched with $\mathrm{CuSO}_{4} \cdot 5 \mathrm{H}_{2} \mathrm{O}$ and $\mathrm{Pb}\left(\mathrm{NO}_{3}\right)_{2}$ in different concentrations. By flame atomic absorption spectrometry (FAAS) it was observed that fungus absorbed $86 \%$ of both copper and lead, with initial concentrations of 100,500 and $1000 \mathrm{mg} \mathrm{L}^{-1}$. The additional results provided by scanning electron microscopy, energy dispersive spectroscopy, and X-ray diffraction showed ability of the microorganism to act as a biosorbent as well as its capacity to transform the tested salts into other inorganic compounds. Chromatographic profile comparison of extracts obtained from the biotic, abiotic control and the cultivation enriched with the metals showed changes in the profile of the secondary metabolism. When the copper and lead salts were tested separately, there was an increase in the production of the compounds as function of the increase of the concentration and when associated promoted the decrease and disappearance of some substances produced by Aspergillus sp.
\end{abstract}

Keywords: Aspergillus, OSMAC, heavy metal, bioremediation potential

\section{Introduction}

The discharge of effluents contaminated with heavy metal ions into rivers, lakes and the soil represents a serious environmental problem experienced by modern society. One of the main sources of contamination by these chemical species is the waste water from the electroplating, smelting, pigmentation, metallurgical and mining industries which can also have further impacts through the construction of dams. $^{1-4}$

In recent years, awareness of the need for rational use of natural resources and the development of technologies that minimize negative impacts on the environment has led to the development of research aimed at recovering areas contaminated by heavy metals. ${ }^{5}$

*e-mail: mno@unifesspa.edu.br
Bioremediation is an example of this, given that it uses microorganisms capable of degrading contaminants from impacted areas with the advantages of being efficient in the removal of metals in low concentrations and having low cost and simplicity in execution. ${ }^{6-11}$

Among the various microorganisms that have been studied for this purpose, filamentous fungi have gained prominence as they are recognized for their potential in degradation, biosorption and resistance to develop under adverse environmental conditions. In particular, fungi of the genus Aspergillus, have showed excellent mechanical properties of their mycelia, good growth rate in high concentrations of heavy metals and high capacity to remove heavy metals from the environment, which makes them a potential tool for use in bioremediation. ${ }^{12-15}$

Motivated by the characteristics already reported, the present work evaluated the potential of Aspergillus sp. 
for bioremediation of environments contaminated by copper and lead. In addition, it analyzed the influence of copper sulfate pentahydrate $\left(\mathrm{CuSO}_{4} \cdot 5 \mathrm{H}_{2} \mathrm{O}\right)$ and lead nitrate $\left[\mathrm{Pb}\left(\mathrm{NO}_{3}\right)_{2}\right]$ salts on the secondary metabolism of the microorganism under investigation. The study of possible modifications in the metabolism of this microorganism on a culture medium is a contribution to the one strainmany compounds (OSMAC) approach, which aims at the production of new substances through the awakening of silenced genes. ${ }^{16-20}$

\section{Experimental}

\section{Microorganism}

The Aspergillus sp. used in this work was isolated from copper mining residue and identified by its morphological characteristics according to manuals described by Klich ${ }^{21}$ and deposited at the multidisciplinary biology laboratory of the Faculdade de Química, Universidade Federal do Sul e Sudeste do Pará.

\section{Experimental apparatus}

A Thermo Scientific iCE 3300 flame atomic absorption spectrometer (FAAS) with deuterium background corrector was used for the determination of $\mathrm{Cu}$ and $\mathrm{Pb}$. All measurements were carried out with an air/acetylene flame. Hollow cathode lamps were used as radiation sources. The wavelengths and current lamps used for determination of $\mathrm{Cu}$, and $\mathrm{Pb}$ were 222.6 and 4; and $217.0 \mathrm{~nm}$ and $4 \mathrm{~mA}$, respectively. The spectral resolutions used were $0.2 \mathrm{~nm}$ for $\mathrm{Cu}$, and $1.0 \mathrm{~nm}$ for $\mathrm{Pb}$. A Milestone Start E closed vessel microwave oven was used for the acid digestion of the biomass after the biosorption process. Scanning electron micrographs and dispersive energy spectra were acquired on Hitachi benchtop microscope (TM 3000, 15 kV) and EDS (energy dispersive spectroscopy) Oxford (ED 3000) coupled. The X-ray diffraction (XRD) analyzes were performed on a Rigaku X-ray diffractometer (MiniFlex600). The high performance liquid chromatographic (HPLC) separations were performed on a Shinm-Pack C18 $(4.6 \times 250 \mathrm{~mm}, 5 \mu \mathrm{m})$ using an Agilent (1260) chromatograph with a photodiode array detector (PDA).

\section{Microculture}

The microculture was carried out with Aspergillus sp. inoculum ( $3 \mathrm{~mL}$ of $10^{6}$ colony-forming units, CFU) in $500 \mathrm{~mL}$ Erlenmeyer flasks containing $300 \mathrm{~mL}$ of a potato dextrose (PD, broth prepared from $300 \mathrm{~g}$ of potato and $20 \mathrm{~g}$ of dextrose and sufficient water to $1 \mathrm{~L}$ ) medium supplemented with copper sulfate pentahydrate $\left(\mathrm{CuSO}_{4} \cdot 5 \mathrm{H}_{2} \mathrm{O}\right)$ and lead nitrate $\left[\mathrm{Pb}\left(\mathrm{NO}_{3}\right)_{2}\right]$ in a final concentrations of 100,500 and $1000 \mathrm{mg} \mathrm{L}^{-1}$. Cultivation was conducted under $150 \mathrm{rpm}$ and $30{ }^{\circ} \mathrm{C}$ shaking for a period of 10 days. The experiment was carried out under aseptic conditions and in triplicate. After the period of growth the mycelium was separated by filtration. Cultivation was developed in two different moments. In the first experiment the goal was to evaluate the potential of biosorption and after cultivation period, were analyzed residual liquid medium and biomass by FAAS. In the second experiment, liquid residual medium in different concentrations of heavy metals, separately and in association, were analyzed for metabolite production by HPLC. The results were compared with those of the control biotic (microorganism and non supplemented culture medium) and abiotic control (culture medium supplemented).

\section{Biosorption experiments}

After cultivation, residual liquid medium in different concentrations were diluted appropriately and the concentration of $\mathrm{Cu}^{2+}$ and $\mathrm{Pb}^{2+}$ remaining in solution was determined by FAAS. All experiments were performed in triplicate. The percent removal of metal ions was calculated using the following equation:

Percentage of removal $=\left(\mathrm{C}_{\mathrm{o}}-\mathrm{C}_{\mathrm{e}}\right) / \mathrm{C}_{\mathrm{o}} \times 100$

where $\mathrm{C}_{\mathrm{o}}$ is the initial metal concentration $\left(\mathrm{mg} \mathrm{L}^{-1}\right) ; \mathrm{C}_{\mathrm{e}}$ is the final metal concentration $\left(\mathrm{mg} \mathrm{L}^{-1}\right)$.

The measurements of copper and lead present in biomass were made from the digestion of $0.25 \mathrm{~g}$ of biomass in a microwave-closed vessel, to which $4 \mathrm{~mL}$ of $50 \%(\mathrm{v} / \mathrm{v})$ $\mathrm{HNO}_{3}$ and $4 \mathrm{~mL}$ of $30 \%(\mathrm{~m} / \mathrm{m}) \mathrm{H}_{2} \mathrm{O}_{2}$ had been added. The microwave heating program consisted of the following steps: $800 \mathrm{~W}$ for $10 \mathrm{~min}$; $800 \mathrm{~W}$ for $15 \mathrm{~min}$; and ventilation for $50 \mathrm{~min}$. The maximum temperature obtained during digestion was $180{ }^{\circ} \mathrm{C}$. The biomasses were completely digested, and the solutions obtained were diluted to $25 \mathrm{~mL}$ with deionized water. All the samples were digested in triplicate. Blank experiments were carried out in the same way. The determinations of copper and lead were performed using FAAS.

For analysis of the surface effects from the fungus/ metal association, the mycelial blanket after growth was submitted to scanning electron microscopy (SEM). In addition, possible structural modifications related to biosorbed metal ions were investigated using EDS and XRD techniques. 


\section{Metabolite production profile}

After 10 days cultivation, $200 \mathrm{~mL}$ ethyl acetate was added to each Erlenmeyer flask. After $24 \mathrm{~h}$ the material was filtered and the organic phase was separated by liquid-liquid partition. The aqueous phase was transferred back to the Erlenmeyer along with mycelium and again $200 \mathrm{~mL}$ of ethyl acetate was added. The extraction was performed three times. The mycelium and aqueous phase were then properly discarded. The organic phase was concentrated in a rotary evaporator under reduced pressure to yield an ethyl acetate extract. This procedure was developed for all cultivation conditions, that is, the PD medium enriched with copper and lead separately, copper and lead in association, biotic and abiotic control. Concerning the OSMAC approach, the chromatographic profiles of the ethyl acetate extracts were investigated from the development of exploratory gradients that were optimized by varying the mobile phase systems $\left(\mathrm{H}_{2} \mathrm{O}: \mathrm{ACN}, \mathrm{H}_{2} \mathrm{O}: \mathrm{MeOH}, \mathrm{MeOH}: \mathrm{ACN}\right)$, flow (0.6, 0.8 and $\left.1.0 \mathrm{~mL} \mathrm{~min}^{-1}\right)$ and temperature $\left(25,30\right.$ and $\left.40{ }^{\circ} \mathrm{C}\right)$. The chromatographic separations were performed by using $20 \mu \mathrm{L}$ of sample at the concentration of $1 \mathrm{mg} \mathrm{L}^{-1}$.

\section{Results and Discussion}

\section{Biosorption potential}

In order to evaluate the potential of bioremediation by Aspergillus sp. the copper and lead contents were measured from the PD culture medium enriched with these metals in concentrations of 100,500 and $1000 \mathrm{mg} \mathrm{L}^{-1}$ after 10 days of cultivation. In addition, the residual biomass, after digestion, was also submitted for evaluation of copper and lead contents.

Aspergillus sp. showed a maximum efficiency of $86 \%$ in the removal of lead when tested at the concentration of $500 \mathrm{mg} \mathrm{L}^{-1}$, as shown in Table 1. The propose for the lowest efficiency measured in the removal of lead when tested in a concentration of $1000 \mathrm{mg} \mathrm{L}^{-1}$ is that probably

Table 1. Data from the lead biosorption study in PD medium

\begin{tabular}{lcccc}
\hline \multicolumn{4}{c}{ Lead biosorption $(\mathrm{Pb})$ by Aspergillus sp. } \\
\cline { 1 - 2 } $\begin{array}{c}\text { Concentration in } \\
\text { the PD / }\left(\mathrm{mg} \mathrm{L}^{-1}\right)\end{array}$ & & $\begin{array}{c}\text { Concentration in the } \\
\text { biosorbent / }\left(\mathrm{mg} \mathrm{L}^{-1}\right)\end{array}$ & $\begin{array}{c}\text { Sorption } \\
\text { efficiency / \% }\end{array}$ \\
\cline { 1 - 2 } Initial & Final & & Biomass & - \\
Control & 0.00 & & 0.00 & 46 \\
100 & $53.9 \pm 5.9$ & & $45.7 \pm 2.1$ & 86 \\
500 & $24.0 \pm 3.7$ & & $431.5 \pm 6.1$ & 78 \\
\hline
\end{tabular}

PD: potato dextrose. the metal in this concentration is capable of inactivating cells responsible for different mechanisms involved in the biosorption processes, such as those involved in the production of extracellular polymeric substances (EPS). ${ }^{22}$

Regarding the sorption of copper, efficiency values ranging from 33 to $86 \%$ were obtained. As the copper concentration increases there is an increase in efficiency in the biosorption process with $86 \%$ as the saturation point of the biomass under the conditions tested. Table 2 shows the initial concentrations used in the evaluation, measured after ten days of cultivation in the PD media, in the residual biomasses, as well as the percentages of sorption.

Table 2. Data from the copper biosorption study in PD medium

\begin{tabular}{|c|c|c|c|}
\hline \multicolumn{4}{|c|}{ Copper biosorption $(\mathrm{Cu})$ by Aspergillus sp. } \\
\hline \multicolumn{2}{|c|}{$\begin{array}{l}\text { Concentration in } \\
\text { the } \mathrm{PD} /\left(\mathrm{mg} \mathrm{L}^{-1}\right)\end{array}$} & \multirow{2}{*}{$\begin{array}{l}\text { Concentration in the } \\
\text { biosorbent } /\left(\mathrm{mg} \mathrm{L}^{-1}\right)\end{array}$} & \multirow{2}{*}{$\begin{array}{c}\text { Sorption } \\
\text { efficiency / \% }\end{array}$} \\
\hline Initial & Final & & \\
\hline Control & 0.00 & 0.00 & - \\
\hline 100 & $59.9 \pm 1.2$ & $32.9 \pm 2.8$ & 33 \\
\hline 500 & $132.5 \pm 2.3$ & $362.5 \pm 6.0$ & 72 \\
\hline 1000 & $82.0 \pm 5.7$ & $862.8 \pm 7.4$ & 86 \\
\hline
\end{tabular}

PD: potato dextrose.

Aspergillus species have been extensively explored for their bioremediation potential, but the maximum efficiency data found in the present investigation are more significant than those reported in the literature under similar experimental conditions. ${ }^{23}$ Thus, the results coming from this study are promising, leading the authors to consider the investigated microorganism as potential tool for recovery of areas affected by heavy metals.

Studies of the morphological characteristics by SEM evidenced modifications on the surface of the fungal biomass compared to the control. Well defined particles of irregular sizes, ripples, cracks, clusters and slight roughness were observed, characterizing, therefore, the presence of more than one phase, as shown in Figure 1. In addition, it is possible to observe that there are smaller particles deposited on the surface of the biomass.

The EDS elemental analyses of the biomasses produced in the different modified cultivation medium confirmed the presence of copper and lead metals in all concentrations tested. The same metals were not found in the biotic control, even if present in the culture medium, were insufficient to be detected, according to the results obtained (Figure 2a). The spectrograms of the biomasses produced in $500 \mathrm{mg} \mathrm{L}^{-1}$ for each metal are shown in Figures $2 \mathrm{~b}$ and $2 \mathrm{c}$. 


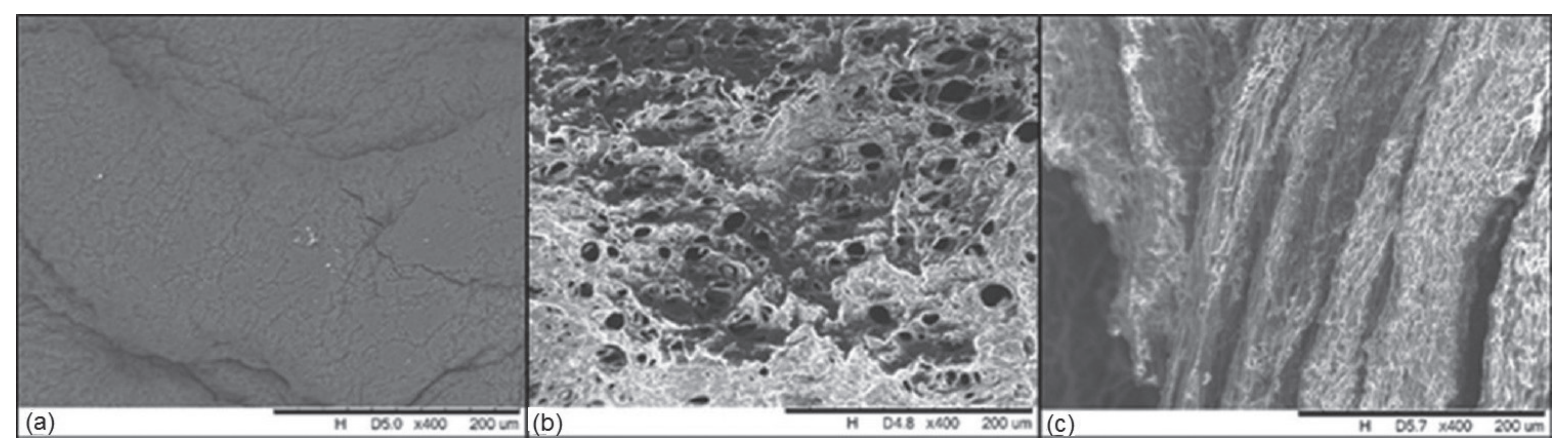

Figure 1. SEM images of fungal biomass under different growing conditions. (a) biotic control; (b) medium enriched with copper (500 $\left.\mathrm{mg} \mathrm{L}^{-1}\right)$; (c) medium enriched with lead (500 $\left.\mathrm{m} \mathrm{L}^{-1}\right)$.

(a)

Spectrum 2
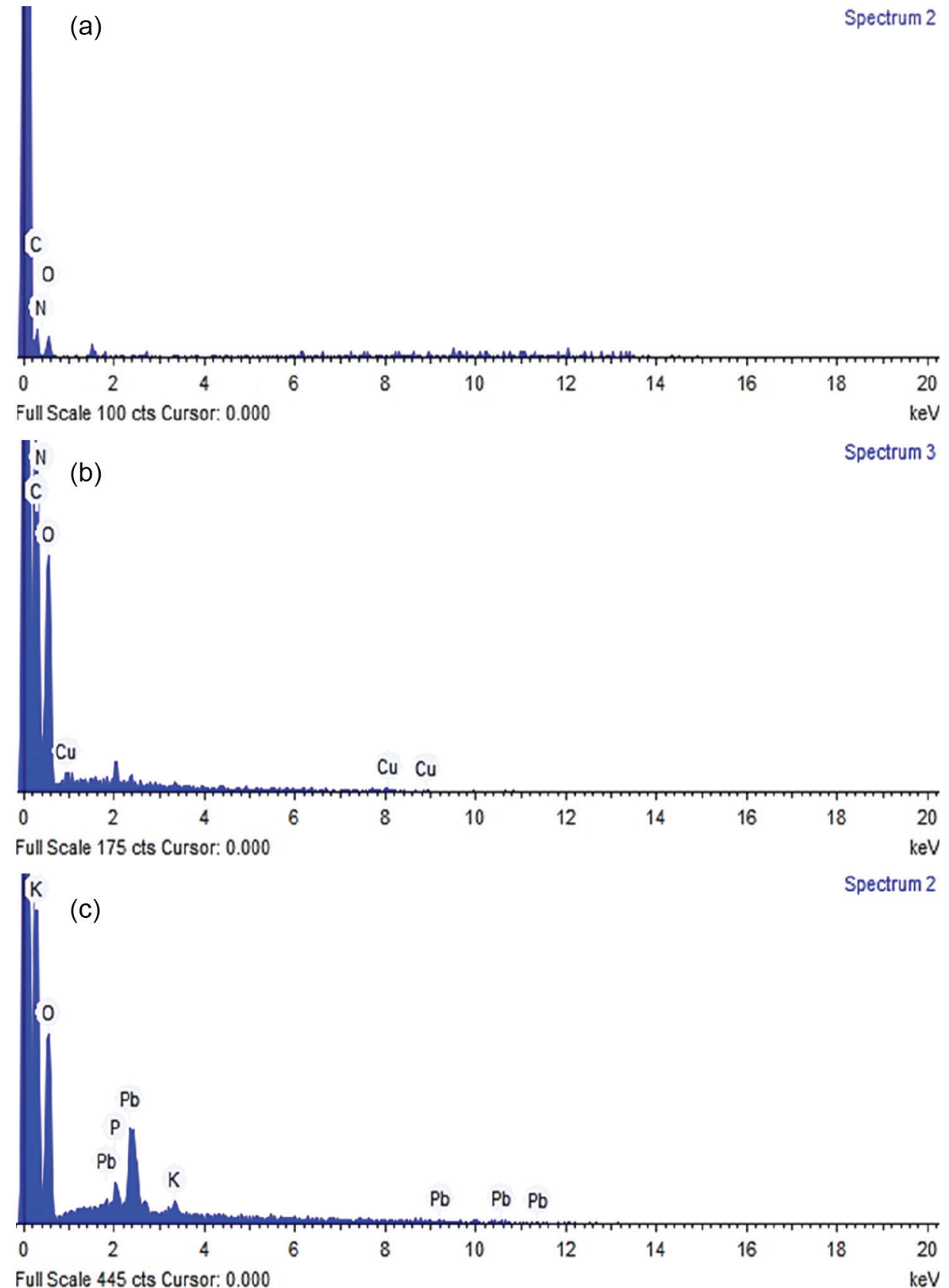

Figure 2. EDS spectra of biomasses produced under different growing conditions. (a) Biotic control; (b) copper (500 $\left.\mathrm{mg} \mathrm{L}^{-1}\right)$; (c) lead (500 mg L $\left.\mathrm{L}^{-1}\right)$. 
SEM and EDS data under all the others cultivations conditions can be analyzed in the Supplementary Information section.

$X R D$ analyses revealed that the starting salts $\left(\mathrm{CuSO}_{4} \cdot 5 \mathrm{H}_{2} \mathrm{O}\right)$ and $\mathrm{Pb}\left(\mathrm{NO}_{3}\right)_{2}$, had undergone biotransformation by the microorganism. In the experiments with copper sulfate, it was possible to detect the presence of copper azide $\left(\mathrm{CuN}_{3}\right)$, copper oxide $\left(\mathrm{Cu}_{2} \mathrm{O}\right)$, copper nitrate $\left(\mathrm{CuNO}_{3}\right)$, copper sulfate $\left(\mathrm{CuSO}_{4}\right)$, among others. The presence of copper azide and copper oxide indicates the oxidation and reduction processes, respectively. In the experiments with lead, the biotransformation of $\mathrm{Pb}\left(\mathrm{NO}_{3}\right)_{2}$ to lead oxide $(\mathrm{PbO})$ was detected. The abiotic control after lyophilization was submitted to the same procedure and the bioproducts were not detected, which provided additional evidence of the microorganism's ability to biotransform the studied salts (Supplementary Information, Figures S15-S17).

The bioproducts copper oxide, copper azide and lead oxide are substances with lower solubility in water compared to their starting salts. The low solubility is an advantageous feature in the bioremediation process. Compounds with low solubility show reduced bioavailability and toxicity. ${ }^{24}$

\section{Profile of metabolite production}

Aspergillus sp. was submitted to different cultivation conditions and the influence of the copper sulfate and lead nitrate salts on the metabolic profile was evaluated. The ethyl acetate extracts obtained from the residual cultivation medium were analyzed by LC under optimal conditions, that is, in an exploratory gradient with mobile phase $\mathrm{H}_{2} \mathrm{O}: \mathrm{ACN}$, temperature of $40{ }^{\circ} \mathrm{C}$, flow of $0.6 \mathrm{~mL} \mathrm{~min}{ }^{-1}$ and wavelength of $280 \mathrm{~nm}$ (optimal in the range of 190-800 nm), in which it was verified greater sensitivity for the majority of the substances present in the extracts.

Comparative studies of chromatographic profiles showed that the stress caused by both salts when tested separately produced similar effects on the metabolism of Aspergillus sp. The increase in the concentration of the salts promoted the increase in the production of the substances, verified as a function of the increase in the intensity of the peaks. These characteristics can be observed from the peaks with retention times close to $10,22,28,44$ and $58 \mathrm{~min}$ (Figure 3a). In addition, the production of substances not detected in the biotic and abiotic control was observed. The peak close to $10 \mathrm{~min}$ in the experiment with copper only appeared in the concentrations of 500 and $1000 \mathrm{mg} \mathrm{L}^{-1}$, as shown in Figure $3 b$.
An analysis of the chromatographic profile of the extracts obtained under the influence of the metals in association in the different concentrations (Figure 3c) shows a sharp decrease in the peak intensity in the concentration $1000 \mathrm{mg} \mathrm{L}^{-1}$. In addition, the disappearance of the peak with retention time close to 10 min suggests that the metals in combination at high concentrations promote a reduction in the metabolic activity of Aspergillus sp.

From the results obtained it can be verified that the OSMAC approach is a potential strategy for obtaining new natural products, as well as for increasing the yield of compounds already known.
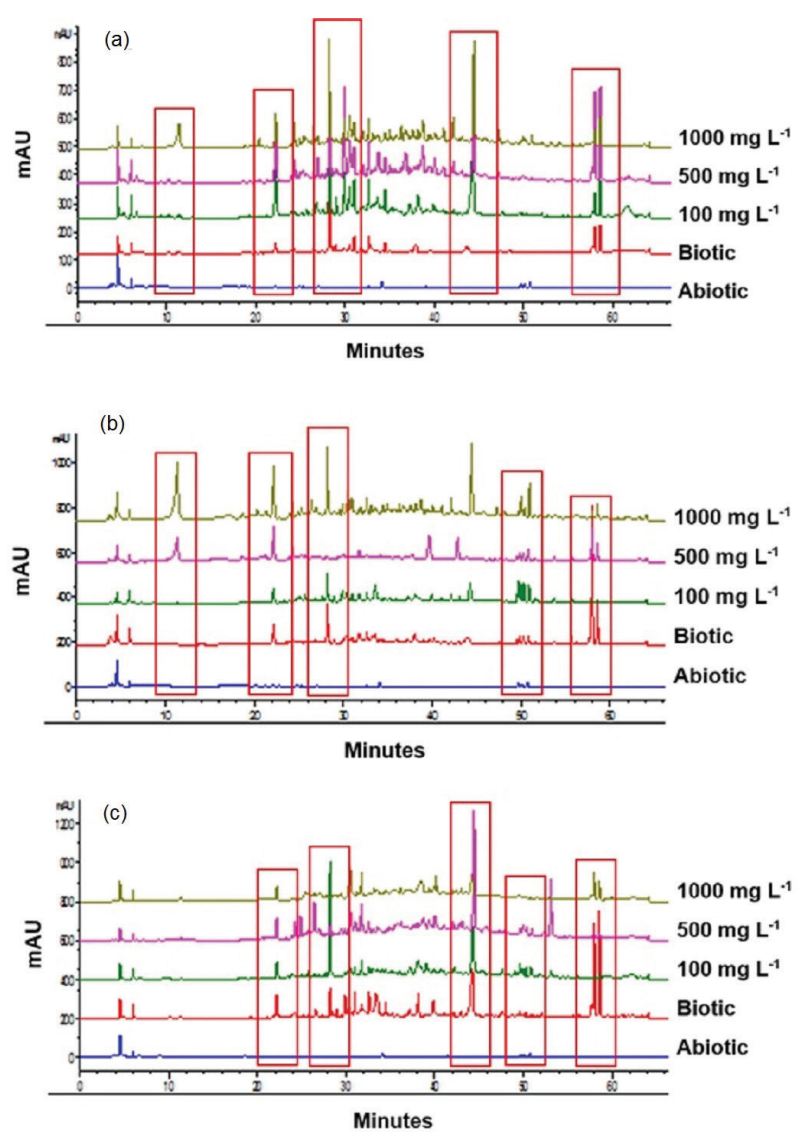

Figure 3. Chromatographic profile of AcOEt extracts obtained from PD media enriched with $\mathrm{CuSO}_{4}, \mathrm{~Pb}\left(\mathrm{NO}_{3}\right)_{2}$ in concentrations of 100,500 and $1000 \mathrm{mg} \mathrm{L}^{-1}$ and biotic and abiotic controls: (a) lead, (b) copper, (c) associated metals.

\section{Conclusions}

The studies performed to evaluate the potential of bioremediation from microcultures enriched with copper and lead using the techniques FAAS, MEV, EDS and XRD proved the ability of Aspergillus sp. to biosorbe the metals under investigation, as well as in biotransform the copper sulfate pentahydrate $\left(\mathrm{CuSO}_{4} .5 \mathrm{H}_{2} \mathrm{O}\right)$ and lead 
nitrate $\left[\mathrm{Pb}\left(\mathrm{NO}_{3}\right)_{2}\right]$ salts into copper oxide, copper azide and lead oxide.

The analysis of the chromatographic profile of the AcOEt extracts obtained from cultures enriched with metals $\left(\mathrm{CuSO}_{4} .5 \mathrm{H}_{2} \mathrm{O}\right)$ and lead nitrate $\left[\mathrm{Pb}\left(\mathrm{NO}_{3}\right)_{2}\right]$ in their different concentrations, promoted changes in the secondary metabolism profile of Aspergillus sp. When tested separately, the increased concentration of the metals promoted the increase of the compounds produced by Aspergillus sp. and under high concentrations, the association of metals promoted the decrease and disappearance of some substances.

From the results obtained, the microorganism Aspergillus sp. demonstrated potential for use as a tool in the bioremediation processes of areas impacted by heavy metals such as copper and lead, developing the functions of biosorbent and biotransformation agent. In addition, changes in the metabolic profile as a response to the variation of the metal salts concentrations corroborated with the OSMAC approach.

\section{Supplementary Information}

Supplementary data (SEM, EDS, XRD) are available free of charge at http://jbcs.sbq.org.br as PDF file.

\section{Acknowledgments}

The authors are grateful to Fundação de Amparo à Pesquisa do Estado do Pará (FAPESPA), Universidade Federal do Pará (UFPA), Universidade Federal de São Carlos (UFSCar), Coordenação de Aperfeiçoamento de Pessoal de Ensino Supeiror (CAPES).

\section{References}

1. Zhou, M.; Lou, J.; Li, Y. K.; Wang, Y. D.; Zhou, K.; Ji, B. K.; Dong, W.; Gao, X. M.; Du, G.; Hu, Q. F.; Arch. Pharmacal Res. 2017, 40, 32.

2. Montoya, V. H.; Cruz, M. A. P.; Castillo, D. I. M.; Virgen, M. R. M.; Petriciolet, A. B.; J. Environ. Manage. 2013, 116, 213.

3. Dinu, M. V.; Dragan, E. S.; Chem. Eng. J. 2010, 160, 157.

4. Qiu, W.; Zheng, Y.; Chem. Eng. J. 2009, 145, 483.

5. Wood, J. L.; Liu, W.; Tang, C.; Franks, A. E.; AIMS Bioeng. 2016, 3, 211.
6. García, R.; Campos, J.; Cruz, J. A.; Calderón, E.; Raynal, E.; Buitrón, G.; TIP, Rev. Espec. Cienc. Quim.-Biol. 2016, 19, 5.

7. Hansda, A.; Kumar, V.; Anshumali.; J. Microbiol. Biotechnol. 2016, 32, 170.

8. Gupta, A.; Joia, J.; Sood, A.; Sood, R.; Sidhu, C.; Kaur, G.; J. Microb. Biochem. Technol. 2016, 8, 364.

9. Praveen, R. S.; Vijayaraghavan, K.; Desalin. Water Treat. 2015, 55, 1816.

10. Bulgariu, L.; Bulgariu, D.; Rusu, C. In Springer Handbook of Marine Biotechnology; Kim, S. K., ed.; Springer: Berlin, 2015, p. 611.

11. Raffar, N. I. A.; Rahman, N. N. A. A.; Alrozi, R.; Senusi, F.; Chang, S. H.; Eng. Ind. 2015, 2015, 70.

12. Aquino, S. F.; Brandt, E. M. F.; Chernicharo, C. A. L.; Eng. Sanit. Ambiental 2013, 18, 187.

13. Andrade, J. D. A.; Augusto, F.; Jardim, I. C. S. F.; Ecletica Quim. 2010, 35, 17.

14. Tonini, R. M. C. W.; Rezende, C. E.; Grativol, A. D.; CEP 2010 , 28013, 602

15. Javaid, A.; Bajwa, R.; Javaid, A.; Pak. J. Bot. 2010, 42, 2105.

16. Ozkaya, F. C.; Ebrahim, W.; Neketi, M. E.; Tanrikul, T. T.; Kalscheuer, R.; Muller, W. E. G.; Guo, Z.; Zou, K.; Liu, Z.; Proksch, P.; Fitoterapia 2018, 131, 9.

17. Wang, H.; Eze, P. M.; Hofert, S. P.; Janiak, C.; Hartmann, R.; Okoye, F. B. C.; Esimone, C. O.; Orfali, R. S.; Dai, H.; Liu, Z.; Proksch, P.; RSC Adv. 2018, 8, 7863.

18. Si, Y.; Tang, M.; Lin, S.; Chen, G.; Feng, Q.; Wang, Y.; Hua, H.; Bai, J.; Wang, H.; Pei, Y.; Tetrahedron Lett. 2018, 59, 1767.

19. Abdelwahab, M. F.; Kurtán, T.; Mándi, A.; Müller, W. E. G.; Fouad, M. A.; Kamel, M. S.; Liu, Z.; Ebrahim, W.; Daletos, G.; Proksch, P.; Tetrahedron Lett. 2018, 59, 2647.

20. Fill, T. P.; Pallini, H. F.; Amaral, L. S.; da Silva, J. V.; Bidóia, D. L.; Peron, F.; Garcia, F. P.; Nakamura, C. V.; Filho, E. R.; J. Braz. Chem. Soc. 2016, 27, 1444.

21. Klich, M. A.; Identification of Common Aspergillus species; American Society for Microbiology: Amsterdam, Netherlands, 2002.

22. Dang, C.; Yang, Z.; Liu, W.; Du, P.; Cui, Feng.; He, K.; J. Environ. Chem. Eng. 2018, 6, 2733.

23. Mishra, A.; Malik, A.; Bioresour. Technol. 2014, 171, 217.

24. Souza, V. L. B.; Lima, V.; Hazin, C. A.; Fonseca, C. K. L.; Santos, S. O.; Braz. J. Rad. Sci. 2015, 3, 1.

Submitted: April 3, 2019

Published online: September 11, 2019 